\title{
Eating disorders symptoms and excessive internet use in adolescents: the role of internalising and externalising problems
}

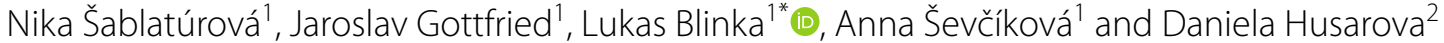

\begin{abstract}
Background: Both eating disorders and excessive internet use represent significant health issues for contemporary adolescents. Yet, the link between them has seldom been investigated. We aim to study this association through their common underlying psychological factors: internalising problems and externalising problems.

Methods: A representative sample of 7,083 adolescents ( $M_{\text {age }}=13.48$ years; $\mathrm{SD}_{\text {age }}=1.32 ; 50.3 \%$ girls) from Slovakia was obtained from the Health Behaviour in School-aged Children (HBSC) project in 2018. Study variables included the Excessive Internet Use Scale (EIU) and the Strength and Difficulties Questionnaire (SDQ). Eating disorders symptoms (EDS) were assessed by SCOFF and selected items from the Eating Disorder Screen for Primary Care (ESP). Data were analysed separately for boys and girls with Structural Equation Modelling.
\end{abstract}

Results: There was a partial correlation between EDS and EIU ( $r=0.36$ for boys and $r=0.29$ for girls) after controlling for the internalising and externalising of problems. Internalising and externalising problems were positively associated with EDS, while EIU was only associated with externalising problems. The results were comparable for both genders.

Conclusion: The study provides evidence that, during adolescence, EDS and EIU are related and have a tendency to occur together. Also, they are related even when controlled for their shared underlying psychological factors, namely the emotional and attentional/behavioural difficulties.

Keywords: Eating disorders symptoms, Excessive internet use, Internalising problems, Externalising problems, Adolescents

\section{Plain English summary}

The study found that, in adolescents, eating disorders symptoms are associated with excessive internet use even when controlled for their shared psychological factors. Self-control issues were associated with both the eating disorder symptoms and excessive internet use, while emotional issues were only associated with the eating disorder symptoms. The strength of the relationship was similar for boys and girls, even though the prevalence of eating disorders symptoms was double in girls.

*Correspondence: lukasblinka@gmail.com

${ }^{1}$ Faculty of Social Studies, Masaryk University, Joštova 10, 60200 Brno, Czech Republic

Full list of author information is available at the end of the article

\section{Introduction}

Adolescence is a life phase that characteristically includes an increased level of risky behaviour and patterns of behaviour that can have a negative impact on health [1]. During this life period, problematic behaviours, risks, and mental health problems often co-occur due to the shared original author(s) and the source, provide a link to the Creative Commons licence, and indicate if changes were made. The images or other third party material in this article are included in the article's Creative Commons licence, unless indicated otherwise in a credit line to the material. If material is not included in the article's Creative Commons licence and your intended use is not permitted by statutory regulation or exceeds the permitted use, you will need to obtain permission directly from the copyright holder. To view a copy of this licence, visit http://creativecommons.org/licenses/by/4.0/. The Creative Commons Public Domain Dedication waiver (http://creativeco mmons.org/publicdomain/zero/1.0/) applies to the data made available in this article, unless otherwise stated in a credit line to the data. 
risk factors, such as internalising tendencies (i.e., emotional) and externalising tendencies (i.e., behavioural) when facing problems [2]. In this paper, we focus on two health risks which are often discussed with respect to current adolescents' health and well-being-eating disorders and excessive internet use. We study these risks in the context of internalising and externalising problems. Although they both have attracted extensive attention, their mutual association has been thoroughly investigated only in a limited number of studies [3, 4].

Eating disorders are characteristic with eating disturbances and rapid weight shifts and represent a significant health issue with potentially severe consequences [5]. Currently, the prevalence of eating disorders is on the rise [6], and it affects more younger ages than in previous decades [5]. According to prior research, gender is an important factor in eating disorders-girls are more likely to experience body-image dissatisfaction and have more desire to control their weight [7]. Even though the prevalence of specific eating disorders (i.e., anorexia nervosa, bulimia nervosa, binge eating disorder), is relatively low-ranging from $0.3 \%$ to $8.7 \%$, varying based on the type, definition, and used methodology [8]. The rates for eating disorder symptomatology and subthreshold forms are even higher [9]. Thus, since our study uses a general representative sample of adolescents, we focus on the symptoms of bulimia and anorexia nervosa (henceforth referred to as eating disorders symptoms, EDS).

Excessive internet use (EIU, also often referred to as internet addiction, problematic internet use) is an umbrella term that represents a range of repetitive impairing behaviours related to the online environment [10], with the characteristic presence of symptoms that are typical for addictive behaviours (e.g., persistent preoccupation, mood changes, difficulties with limiting time online, subsequent conflicts [11]). EIU has been shown to be linked to problematic usage patterns, such as computer gaming [12] and the use of social networking sites [13]. Generally, the usage patterns are different for boys and girls - while boys prefer gaming, girls lean towards using social networking [14]. The prevalence of EIU varies considerably depending on the sample and the measuring tool [15]; however, high-quality studies usually report prevalence at a few percentage points (e.g., 2.6\% [13]). EIU was shown to be associated with a rather large spectrum of difficulties, including diminished well-being, emotional and behavioural difficulties, school problems, sleep disturbances, and dietary problems $[11,16]$.

Several studies have indicated that EIU may negatively affect eating habits [17], and reduce physical activity, and thus increase the risk of being overweight and obese [18]. However, weight-loss and/or internalization of thinideal associated with bulimia and anorexia nervosa (the symptoms focused upon in this paper) in relationship to EIU may be less apparent. A meta-analysis [19] found an association between social-networking-site use and the internalization of a thin ideal, suggesting that constant exposure to unrealistic body ideals may trigger body dissatisfaction and the need to modify eating habits [20]. However, according to some studies [21], EDS are not isolated phenomena, and the source of the problem lies in the psycho-emotional and social characteristics of the adolescent. Specifically, EDS and EIU may largely overlap due to the fact that they share risk factors and underlying psychological principles, such as behavioural responses like externalising problems (i.e., impulsivity, lower selfcontrol, ADHD) and emotional responses like internalising problems (i.e., depressive symptoms, anxiety, lower self-esteem). In the case of EIU, lower self-control is associated with being prone to immediate gratification, which may become problematic when met with emotional problems because they increase the need to get relief. Easy gratification (which is a dysfunctional coping strategy) may become habitual and further contribute to the escalation of problems [22]. In the case of EDS, the internalising link has been confirmed in many studies. Specifically, EDS was found to be associated with, or even predicted by, social withdrawal, depressive symptoms, nervousness, loneliness, feelings of inferiority, and guilt [23]. The association of EDS and externalising problems was not investigated to the extent that it has a link with emotional problems; however, it was found to be a factor in bulimic symptomatology and binge- eating disorder [24].

Nonetheless, to our knowledge, no study has jointly examined behavioural (i.e., externalizing) and emotional (i.e., internalizing) problems in relation to EDS and EIU, while also taking into consideration possible gender differences. In this paper, we test such a model with a large-scale representative national sample of Slovak adolescents. We aim to investigate the linkages for the individual internalisation and externalisation of problems in association with EIU and the symptoms of eating disorders, separately for girls and boys, to get a more widespread understanding of how adolescents' digital life is related to the symptoms of eating disorder and problematic eating behaviour.

\section{Methods \\ Participants}

Data were obtained from the World Health Organization (WHO) and its collaborative Health Behaviour in Schoolaged Children (HBSC) study, which was conducted in Slovakia in 2018. To obtain a representative sample of school children aged 11-16, 140 schools (randomly selected from the list of all eligible schools in Slovakia) 
were invited. A total of 109 agreed to participate in our survey. The school response rate (RR) was $77.85 \%$. Consequently, a representative sample of 8,405 adolescents in Slovakia was obtained ( $R R=56.7 \%)$. The sample for this study comprises of 7,083 adolescents (mean age: 13.48 years; $50.3 \%$ girls).

Participation was fully voluntary with no explicit incentives. When schools agreed to participate in our survey, parents of all students in the 5th, 7th and 9th grades were informed about the study by the school administration, they could opt-out if they disapproved of their child's participation. Plus, the pupils themselves were given the opportunity to not participate in the data collection even if their parents consented. The data were collected anonymously with an electronic questionnaire that was administered in the school by a team of trained administrators and in the absence of teachers.

Based on a relatively high rate of missing data for items regarding excessive internet use (approximately 15-18\%, we argue the high missing rate was caused by positioning the items near the end of the questionnaire), we decided to exclude all data from respondents who answered less than two out of five respective items. The majority of the excluded cases were respondents who quit the questionnaire before completion. The rationale for this listwise data exclusion was the potentially significant bias of the pairwise SEM estimating method, which requires data to be missing completely at random. This assumption was clearly not met. Because the imputation of data with high missing rates is also prone to bias, we decided to sacrifice the final sample size in favour of a more robust and precise estimation. After this exclusion, the total sample size dropped considerably to 7,083 , from 8,405 (almost $16 \%$ of the sample). As the rate of missing data for all items was now $<4 \%$, we imputed any remaining missing data via the multiple imputation method, using the proportional odds model and the logistic regression model due to the presumably ordinal or binary nature of certain item scale answers. The imputed dataset used for this study is included in Additional file 1.

\section{Measures}

Data for the present analyses were collected using questionnaires from the standardized research protocols for the 2017/2018 WHO-collaborative HBSC study [25], except for the Excessive Internet Use Scale, which was used only in Slovakia. For this study, we used the following measures (items were reversed so that higher scores represent higher EDS, EIU, externalising problems, and internalising problems, respectively).

Eating Disorder Symptoms was measured using seven items. The measure was created using the SCOFF questionnaire, a five-item screening tool designed to identify potential eating disorder pathology and to suggest whether an eating disorder might be present [26] and two items from Eating Disorder Screen for Primary Care (ESP) [27] that are typically used for the screening of bulimia nervosa. Participants were asked if they worry that they have lost control over how much they eat, whether they ever make themselves sick because they feel uncomfortably full, if they believe that they are fat when others say they are too thin, and whether they would say that food dominates their life. The fifth item, "weight loss", was reformulated because the original weight unit, "stone", is not used in the Slovak language. Therefore, participants were asked if they lost more than six kilograms in three months. The items used from ESP included questions: 'Are you satisfied with your eating patterns?' and 'Do you ever eat in secret?' Seven dichotomous answers (i.e., yes/no, scored $1 / 0$, possible sum score range 0-7) were used to estimate a factor score of EDS for each participant.

Excessive internet use was measured using the five-item Excessive Internet Use Scale (created within the EU Kids Online network; eukidsonline.net), which was validated in 25 European countries [11]. The scale was constructed to capture the symptoms of the components of the model of behavioural addiction (i.e., salience, withdrawal symptoms, relapse, tolerance, conflict [28]). Using a 4-point scale ranging from never (1) to very often (4), participants rated how often they had experienced such internet use (i.e., not limited to a specific online application) in the preceding 12 months. Possible sum score range was $5-20$ and the scale alpha was 0.79 . The answers were treated as ordinal when calculating a factor score for each respondent.

Externalising and Internalising problems were assessed using a two-factor solution from the Strengths and Difficulties Questionnaire (SDQ; [29]). The two-factor solution (instead of four factors) was used for better application to cases with lower scores (i.e., in a general rather than clinical population) [30]. The internalising subscale contained 10 items to measure emotional symptoms and peer difficulties. The externalising subscale contained 10 items to measure behavioural problems and impulsivity/hyperactivity. Items were rated on a 3-point scale (i.e., not true, somewhat true, and certainly true; possible sum score range 10-30 for each subscale). Cronbach's alpha equalled 0.68 for the internalising problems subscale and 0.67 for the externalising problems subscale, which indicates acceptable, albeit poorer internal consistency-similar scores were reported in other studies [30].

\section{Statistical analysis}

Structural Equation Modelling (SEM) was used to assess the relationships among the studied variables 
in R software, version 4.0.2 ( $\mathrm{R}$ Core Team, 2020), with package "lavaan" [31]. We predicted EDS and EIU with both externalising and internalising problems and estimated the partial correlation between EDS and EIU. Due to reasonable assumptions, we also tested for measurement invariance for boys and girls, aiming for metric invariance that would allow us to compare standardized regression and correlation coefficients between the genders. Due to the low range of response scales $(0-1$ for EDS, $1-3$ for internalising and externalising problems, and 1-4 for EIU), we treated data as ordinal, used theta parameterization, and weighted the least square mean and variance adjusted (WLSMV) estimator.

First, we fitted four simple measurement models separately, each with only one latent variable (i.e., EDS, EIU, Externalising problems, Internalising problems) and the respective questionnaire items. Based on modification indices, we examined the items. Following this step, we allowed for correlated residual variance between several pairs of items within each scale, based on their phrasing or content similarity. After this procedure, all measurement models (except for the EIU measurement model, for which no correlated residual variance would considerably improve its fit) were significantly improved regarding their fit to the data. We implemented the aforementioned residual covariance terms into the SEM invariance models. We employed model fit evaluation rules based on a recommendation from prior study [32] by evaluating TLI and SRMR indices together and, based on their findings, we consider TLI $\geq 0.95$ and $\mathrm{SRMR} \leq 0.06$ to be a good fit, $\mathrm{TLI} \geq 0.90$ and $\mathrm{SRMR} \leq 0.08$ to be an acceptable fit, and $\mathrm{TLI}<0.90$ and SRMR $>0.08$ to be a poor fit. Regarding SEM invariance testing, as suggested in guidelines [33], we set $\Delta C F I=-0.01$ to be the maximum acceptable fit impairment. We considered the Likelihood-Ratio test to be unreliable in this case, because of its susceptibility to be biased in large samples. The $\mathrm{R}$ script of our analysis is included in Additional file 2.

\section{Results}

Table 1 shows the mean, minimum, and maximum score values, and the standard deviations of key variables for each gender in the original data set. Based on the sum score computed from the five original SCOFF questionnaire items and its established cut-off score of $2 / 3$ [34], 267 (7.8\%) boys and 489 (14.2\%) girls could be classified as being at risk for an eating disorder-this serves as an approximate assurance that the SCOFF items themselves are performing in an expected way, because the rates in
Table 1 Descriptive statistics of the study variables in the original data set

\begin{tabular}{lrrrr}
\hline & M & SD & Minimum & Maximum \\
\hline Boys & & & & \\
$\quad$ Excessive internet use & 7.72 & 3.16 & 5.00 & 20.00 \\
$\quad$ Eating disorders symptoms & 1.65 & 1.29 & 0.00 & 7.00 \\
Internalising problems & 14.48 & 3.13 & 10.00 & 29.00 \\
$\quad$ Externalising problems & 16.41 & 3.23 & 10.00 & 29.00 \\
Girls & & & & \\
$\quad$ Excessive internet use & 7.65 & 2.74 & 5.00 & 20.00 \\
Eating disorders symptoms & 2.15 & 1.46 & 0.00 & 7.00 \\
Internalising problems & 15.77 & 3.43 & 10.00 & 28.00 \\
$\quad$ Externalising problems & 16.60 & 3.35 & 10.00 & 28.00 \\
\hline
\end{tabular}

$\mathrm{N}$ boys $=2,891 ; \mathrm{N}$ girls $=2,898$

our survey are similar to the prevalence reported in previous studies [6].

\section{Structural equation modelling results}

Regarding measurement models, the EIU and SDQ externalizing problem measures showed a good fit for the data, the SDQ internalizing problem measure showed an acceptable fit, and the EDS measure model fitted the data poorly, see Table 2 for detailed fit indices. We ascribe the poor EDS measurement performance to its screening nature, which resulted in weak factor loading on the items. Surprisingly, the two ESP items showed much better factor loadings than certain SCOFF items. We include the EDS item factor loadings in Additional file 3. Alongside TLI and SRMR for indicating a quality of model fit, we report CFI for assessing a change in fit across invariance models, and also RMSEA as a customary addition.

We tested the model for invariance across both genders. First, we tested for configural invariancewhether the pattern of factor loadings is roughly the same. This model showed acceptable-to-great fit for the data, $\chi^{2}(898)=5282.4, C F I=0.953, T L I=0.948$, RMSEA $=0.037, \quad S R M R=0.057$. We conclude that the configural invariance has been achieved. Then, we tested for the threshold invariance-whether the binary and ordinal items had identical thresholds. Since the CFI of this model remained practically the same as for the configural model, we conclude that the threshold invariance had been achieved. In the same way, because $\Delta \mathrm{CFI}=-0.002$, we conclude that we achieved metric invariance-whether or not the factor loadings on items are identical. However, scalar invariance-the equality of item intercepts-was not achieved, $\triangle \mathrm{CFI}=-0.11$. Table 2 contains further details about the characteristics of the invariance models. Nevertheless, since the 
Table 2 Fit indices of study measures and tested models

\begin{tabular}{|c|c|c|c|c|c|c|}
\hline & $x^{2}$ & df & CFI & TLI & RMSEA & SRMR \\
\hline \multicolumn{7}{|l|}{ Measurement models } \\
\hline Excessive internet use & 92.37 & 5 & 0.996 & 0.992 & 0.050 & 0.029 \\
\hline Eating disorder symptoms & 246.94 & 13 & 0.907 & 0.849 & 0.050 & 0.040 \\
\hline Internalising problems & 795.50 & 33 & 0.948 & 0.929 & 0.057 & 0.063 \\
\hline Externalising problems & 421.76 & 31 & 0.972 & 0.959 & 0.042 & 0.044 \\
\hline \multicolumn{7}{|l|}{ Measurement invariance testing } \\
\hline Configural invariance by gender & 5282.39 & 898 & 0.953 & 0.948 & 0.037 & 0.057 \\
\hline Thresholds invariance by gender & 5284.53 & 903 & 0.953 & 0.949 & 0.037 & 0.057 \\
\hline Metric invariance by gender & 5578.29 & 931 & 0.951 & 0.947 & 0.038 & 0.059 \\
\hline Scalar invariance by gender & 6559.00 & 952 & 0.940 & 0.938 & 0.041 & 0.060 \\
\hline
\end{tabular}

model shows metric invariance, we can compare standardized regression and correlation coefficients between latent variables for boys and girls.

When inspected, the mutual latent variable relationships can be considered of more or less equal strength across both genders. In this regard, Fig. 1 shows the standardized regression and correlation coefficients for boys and girls, respectively.

Both dimensions of SDQ were strongly positively crosscorrelated (boys: $r=0.78$; girls: $r=0.76$ ) and positively associated with $\operatorname{EDS}(\beta=0.34 ; \beta=0.35$ for externalising problems, $\beta=0.25 ; \beta=0.35$ for internalising problems, for boys and girls, respectively), but only externalising problems positively predicted EIU ( $\beta=0.56$ for boys and $\beta=0.49$ for girls), while internalising problems did not $(\beta=-0.08$ for boys; $\beta=0.09$ for girls). Even after considering these predictors, a weak positive partial correlation remained between EDS and EIU for both boys and girls ( $r=0.36$ and $r=0.29$, respectively). This partial correlation shows the strength of association after controlling for associations with both the externalising and internalising problems.

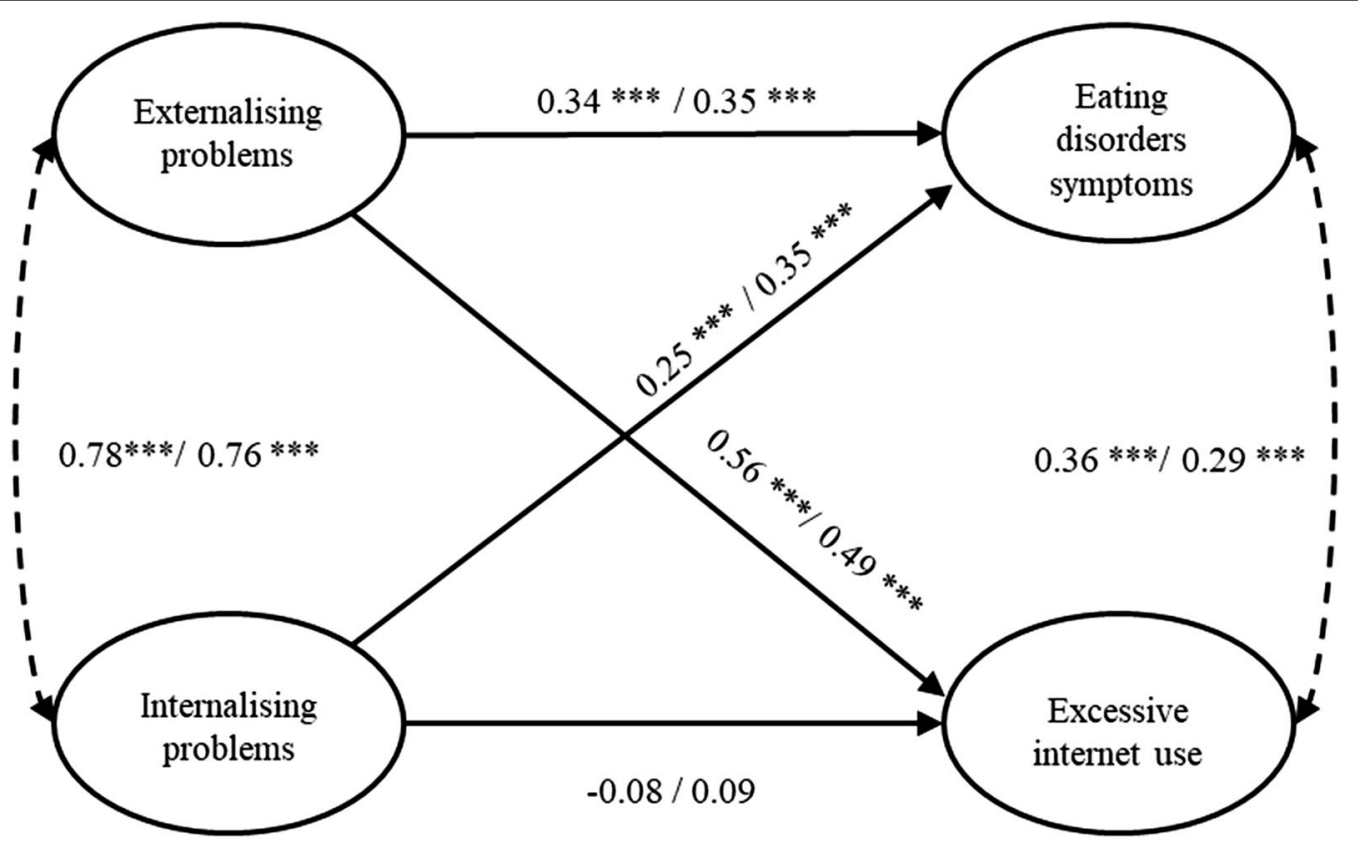

Fig. 1 Final model with the standardized regression and correlation coefficients for boys and girls, respectively 


\section{Discussion}

In line with the research purpose, this study tested the association between EDS and EIU while taking into consideration internalising and externalising problems as shared factors. Three main findings emerged. First, there remained a partial correlation between EDS and EIU after controlling for externalising and internalising dimensions of SDQ. Second, only externalising problems were associated with both EDS and EIU, while EDS was associated with both externalising and internalising problems. Third, the findings were comparable for both genders, boys and girls.

The first result expands upon the existing literature for the association between EDS and EIU [4] in that these two risks remain partially correlated, pointing to other unexplained mechanisms (not included in the present study) that are responsible for their co-occurrence. We suggest that family-related factors (e.g., parental care, parental monitoring, family dysfunction, family eating habits) might be explanatory factors; indeed, former studies already reported its effects on EDS [35] as well as on EIU [36]. Nevertheless, more research is needed to disentangle the associations between EIU and other forms of EDS.

The second finding points to externalising problems as the only path that relates to both EDS and EIU. Externalising problems is characterised by increased levels of behavioural difficulties, impulsivity, and hyperactivity, suggesting the linkage between EDS and EIU may be enhanced by poorer self-control mechanisms and a tendency to rash action, or sensation seeking [22, 37]. EDS was associated with both externalising and internalising problems, which is consistent with prior literature [37, 38] However, internalising problems lost its effect in the case of EIU, which is not consistent with what had been found before [39]. Nonetheless, it is important to bear in mind that externalising and internalising problems were strongly correlated in this study such that we can presume that, due to the relatively strong effect of externalising problems towards the EIU, the internalising problems lost impact in our model. But that does not mean that emotional difficulties played no role in EIU-rather that they share their effect through the impulsivity/externalising pathway. This indicates that the 'impulsivity' pathway dominates in the case of EIU while there may be at least two pathways for EDS (i.e., the impulsive and emotional, since they both kept their effect).

The third result is a novel finding that suggests that the tested associations between the measured constructs were comparable for boys and girls. This is surprising because boys and girls have different patterns of internet use. The most established digital media activity associated with EDS is social media use [4], which has a higher prevalence among girls [14] compared to boys, who are likely to play games [40]. But based on our results, we may hypothetically assume that the associations among the studied constructs are similar regardless of the preferred digital activity. However, the specific online behaviour and the relation of EIU to a specific online application was not measured here and, as suggested [41], the mechanisms, that affect EDS, might vary depending on the specific online activity in which the user engages.

Importantly, there are other limitations that should be noted. The cross-sectional design of this study limits the conclusive statements about the causality between our variables, which could not be established based on our study design. Also, only self-reported questionnaires were used, which could lead to a reporting bias. Furthermore, since data come from an epidemiological survey for which the use of short screening measures is typical, the scale to measure EIU contained only five items and the scale to measure EDS contained only seven items. EDS was measured with the items that consisted largely of that SCOFF instrument that has, akin to other community samples, lower internal consistency, and this has been showed to have rather lower sensitivity in large community samples [42], which was also our case. The EDS measurement used in our study assessed the risk of developing eating problems rather than specific mental health disorders. Moreover, the EIU scale measured generalised excessive internet use and did not assess specific online behaviours; the mechanism of their effect might be modified by the particular facet of the internet [41]. The existence of generalized internet addiction has been criticized and, according to some authors, it is comprised of a combination of various specific internet addictions (e.g., gaming, social networking), rather than an independent concept [43]. However, we did not consider EIU as a separate phenomenon, but as an umbrella term for various internet-based addictions that could not be measured separately in a large-scale epidemiological research project.

\section{Conclusion}

Using a large national representative sample of adolescents with a high response rate, this study confirmed a partial correlation between the EDS and EIU for both genders. This study also showed that externalising problems (i.e., having a poorer control mechanism) are a shared factor for both the EDS and EIU. Therefore, externalising problems in adolescents should be addressed in prevention and intervention efforts. 


\section{Abbreviations}

HBSC: Health behavior in school-aged children; EDS: Eating disorders symptoms; EIU: Excessive internet use; SDQ: Strength and difficulties questionnaire.

\section{Supplementary Information}

The online version contains supplementary material available at https://doi. org/10.1186/s40337-021-00506-5.

Additional file 1: Imputed data.

Additional file 2: $\mathrm{R}$ script.

Additional file 3: Factor loadings of EDS.

\section{Acknowledgements}

None.

\section{Authors' contributions}

NŠ wrote the first draft, JG conducted the statistical analysis and wrote the analytical part, LB and $A \breve{S}$ made the study concept and design, LB, AŠ, NŠ interpreted the results, $L B, A \breve{S}, \mathrm{DH}$ supervised the study, DH participated in data collection and management. All the authors had a full access to the data in the study and were responsible for the integrity of the data and the accuracy of the data analysis. All authors read and approved the final manuscript.

\section{Funding}

This work was supported by the Slovak Research and Development Support Agency under Contract No. APVV-15-0012 and APVV-18-0070, the Scientific Grant Agency of the Ministry of Education, Science, Research and Sport of the Slovak Republic and the Slovak Academy of Sciences, Reg. No. 1/0177/20, and by Masaryk University (MUNI/A/1564/2020)

\section{Availability of data and materials}

Data are available with the manuscript.

\section{Declarations}

\section{Ethics approval and consent to participate}

The study was approved by the Ethics Committee of the Medical Faculty at the Pavol Jozef Safarik University in Kosice, Slovak Republic (16 N/2017). Informed, passive consent was obtained by- all of the participants and their parents had the opportunity disallow participation in this study. Passive consent was sufficient because the data were obtained completely anonymously and no personalized data were collected.

\section{Consent for publication}

Not applicable.

\section{Competing interests}

The authors declare no competing interests.

\section{Author details}

${ }^{1}$ Faculty of Social Studies, Masaryk University, Joštova 10, 60200 Brno, Czech Republic. ${ }^{2}$ Department of Health Psychology and Methodology Research, Faculty of Medicine, P.J. Safarik University in Kosice, Košice, Slovakia.

Received: 23 July 2021 Accepted: 2 November 2021

Published online: 21 November 2021

\section{References}

1. Steinberg L. A social neuroscience perspective on adolescent risk-taking. Dev Rev. 2008. https://doi.org/10.1016/j.dr.2007.08.002.

2. Jessor R, Jessor SL. Problem behavior and psychological development: a longitudinal study of youth. New York: Academic Press; 1977.
3. Hinojo-Lucena FJ, Aznar-Díaz I, Cáceres-Reche MP, Trujillo-Torres JM, Romero-Rodríguez JM. Problematic internet use as a predictor of eating disorders in students: a systematic review and meta-analysis study. Nutrients. 2019. https://doi.org/10.3390/nu11092151.

4. Ioannidis K, Taylor C, Holt L, Brown K, Lochner C, Fineberg NA, Czabanowska K. Problematic usage of the internet and eating disorders: a multifaceted, systematic review and meta-analysis. Neurosci Biobehav Rev. 2021. https://doi.org/10.1101/2020.08.20.20177535.

5. Schmidt U, Adan R, Böhm I, Campbell IC, Dingemans A, Ehrlich S, Zipfel S. Eating disorders: the big issue. Lancet Psychiatry. 2016. https://doi.org/10. 1016/s2215-0366(16)00081-x.

6. Galmiche M, Déchelotte P, Lambert G, Tavolacci MP. Prevalence of eating disorders over the 2000-2018 period: a systematic literature review. Am J Clin Nutr. 2019. https://doi.org/10.1093/ajcn/nqy342.

7. Bašková M, Holubčíková J, Baška T. Body-image dissatisfaction and weight-control behaviour in Slovak adolescents. Cent Eur J Public Health. 2017. https://doi.org/10.21101/cejph.a4724.

8. Dahlgren $C L$, Wisting $L, R \varnothing \varnothing$. Feeding and eating disorders in the DSM-5 era: a systematic review of prevalence rates in non-clinical male and female samples. J Eat Disord. 2017. https://doi.org/10.1186/ s40337-017-0186-7.

9. Smink FRE, van Hoeken D, Hoek HW. Epidemiology of eating disorders: incidence, prevalence and mortality rates. Curr Psychiatry Rep. 2012. https://doi.org/10.1007/s11920-012-0282-y.

10. Fineberg N, Demetrovics Z, Stein D, loannidis K, Potenza M, Grünblatt E, Chamberlain S. Manifesto for a European research network into Problematic Usage of the Internet. Eur Neuropsychopharmacol. 2018. https://doi. org/10.1016/j.euroneuro.2018.08.004.

11. Škařupová K, Ólafsson K. Blinka L Excessive internet use and its association with negative experiences: quasi-validation of a short scale in 25 European countries. Comput Hum Behav. 2015. https://doi.org/10.1016/j. chb.2015.06.047.

12. Blinka L, Škařupová K, Ševčíková A, Wölfling K, Müller KW, Dreier M. Excessive internet use in European adolescents: What determines differences in severity? Int J Public Health. 2014. https://doi.org/10.1007/ s00038-014-0635-x

13. Müller KW, Dreier M, Beutel ME, Duven E, Giralt S, Wölfling K. A hidden type of internet addiction? Intense and addictive use of social networking sites in adolescents. Comput Hum Behav. 2016. https://doi.org/10. 1016/j.chb.2015.09.007.

14. Kuss DJ, Griffiths MD. Social networking sites and addiction: ten lessons learned. Int J Environ Res Public Health. 2017. https://doi.org/10.3390/ ijerph14030311.

15. Pan YC, Chiu YC, Lin YH. Systematic review and meta-analysis of epidemiology of internet addiction. Neurosci Biobehav Rev. 2020. https://doi.org/ 10.1016/j.neubiorev.2020.08.013.

16. Ho RC, Zhang MW, Tsang TY, Toh AH, Pan F, Lu Y, Mak K-K. The association between internet addiction and psychiatric co-morbidity: a meta-analysis. BMC Psychiatry. 2014. https://doi.org/10.1186/1471-244x-14-183.

17. Holland G, Tiggemann M. "Strong beats skinny every time": Disordered eating and compulsive exercise in women who post fitspiration on Instagram. Int J Eat Disord. 2017. https://doi.org/10.1002/eat.22559.

18. Bozkurt H, Özer S, Sahin S, Sönmezgöz E. Internet use patterns and Internet addiction in children and adolescents with obesity. Pediatr Obes. 2017. https://doi.org/10.1111/ijpo.12216.

19. Mingoia J, Hutchinson AD, Wilson C, Gleaves $\mathrm{DH}$. The relationship between social networking site use and the internalization of a thin ideal in females: a meta-analytic review. Front Psychol. 2017. https://doi.org/10. 3389/fpsyg.2017.01351.

20. Tiggemann M, Zaccardo M. "Exercise to be fit, not skinny": the effect of fitspiration imagery on women's body image. Body Image. 2015. https:// doi.org/10.1016/j.bodyim.2015.06.003.

21. Ferguson CJ, Muñoz ME, Garza A, Galindo M. Concurrent and prospective analyses of peer, television and social media influences on body dissatisfaction, eating disorder symptoms and life satisfaction in adolescent girls. J Youth Adolesc. 2014. https://doi.org/10.1007/s10964-012-9898-9.

22. Brand M, Wegmann E, Stark R, Müller A, Wölfling K, Robbins TW, Potenza MN. The Interaction of Person-Affect-Cognition-Execution (I-PACE) model for addictive behaviors: update, generalization to addictive behaviors beyond internet-use disorders, and specification of the process character 
of addictive behaviors. Neurosci Biobehav Rev. 2019. https://doi.org/10. 1016/j.neubiorev.2019.06.032.

23. Adambegan M, Wagner G, Nader IW, Fernandez-Aranda F, Treasure J, Karwautz A. Internalizing and externalizing behaviour problems in childhood contribute to the development of anorexia and bulimia nervosa-a study comparing sister pairs. Eur Eat Disord Rev. 2012. https://doi.org/10. 1002/erv.1152.

24. Collier DA, Treasure JL. The aetiology of eating disorders. Br J Psychiatry. 2004. https://doi.org/10.1192/bjp.185.5.363.

25. Inchley J, Currie D, Cosma A. Samdal O Health Behaviour in School-aged Children (HBSC) Study Protocol: background, methodology and mandatory items for the 2017/18 survey. Child and Adolescent Health Research Unit (CEHRU): University of St Andrews; 2018.

26. Morgan J, Reid F, Lacey J. The SCOFF questionnaire: assessment of a new screening tool for eating disorders. BMJ. 1999. https://doi.org/10.1136/ bmj.319.7223.1467.

27. Cotton M-A, Ball C, Robinson P. Four simple questions can help screen for eating disorders. J Gen Intern Med. 2003. https://doi.org/10.1046/j.15251497.2003.20374.x.

28. Griffiths M. A'components' model of addiction within a biopsychosocial framework. J Substance Use. 2005. https://doi.org/10.1080/1465989050 0114359.

29. Goodman R. The strengths and difficulties questionnaire: a research note. J Child Psychol Psychiatry. 1997. https://doi.org/10.1111/j.1469-7610. 1997.tb01545.x.

30. Goodman A, Lamping DL, Ploubidis GB. When to use broader internalising and externalising subscales instead of the hypothesised five subscales on the Strengths and Difficulties Questionnaire (SDQ): data from British parents, teachers and children. J Abnorm Child Psychol. 2010. https://doi.org/10.1007/s10802-010-9434-x.

31. Rosseel Y. lavaan: AnRPackage for structural equation modeling. J Stat Softw. 2012. https://doi.org/10.18637/jss.v048.i02.

32. Hu L, Bentler PM. Cutoff criteria for fit indexes in covariance structure analysis: conventional criteria versus new alternatives. Struct Equ Model. 1999. https://doi.org/10.1080/10705519909540118.

33. Cheung GW, Rensvold RB. Evaluating goodness-of-fit indexes for testing measurement invariance. Struct Equ Model. 2002. https://doi.org/10. 1207/S15328007SEM0902_5.

34. Hill LS, Reid F, Morgan JF, Lacey JH. SCOFF, the development of an eating disorder screening questionnaire. Int J Eat Disord. 2009. https://doi.org/ 10.1002/eat.20679.
35. Langdon-Daly J, Serpell L. Protective factors against disordered eating in family systems: a systematic review of research. J Eat Disord. 2017. https:// doi.org/10.1186/s40337-017-0141-7.

36. Faltýnková A, Blinka L, Ševčíková A, Husarova D. The Associations between family-related factors and excessive internet use in adolescents. Int J Environ Res Public Health. 2020. https://doi.org/10.3390/ijerph1705 1754.

37. Lavender JM, Mitchell JE. Eating disorders and their relationship to impulsivity. Curr Treat Options Psychiatry. 2015. https://doi.org/10.1007/ s40501-015-0061-6.

38. Zeiler M, Waldherr K, Philipp J, Nitsch M, Dür W, Karwautz A, Wagner G Prevalence of eating disorder risk and associations with health-related quality of life: results from a large school- based population screening. Eur Eat Disord Rev. 2015. https://doi.org/10.1002/erv.2368.

39. Tang J, Yu Y, Du Y, Ma Y, Zhang D, Wang J. Prevalence of internet addiction and its association with stressful life events and psychological symptoms among adolescent internet users. Addict Behav. 2014. https://doi.org/10. 1016/i.addbeh.2013.12.010.

40. Smahel D, Machackova H, Mascheroni G, Dedkova L, Staksrud E, Ólafsson K, Livingstone S, Hasebrink U. EU kids online 2020: survey results from 19 countries. EU Kids Online. 2020. https://doi.org/10.21953//se.47fdeaj01o fo.

41. Ioannidis K, Chamberlain SR. Digital hazards for feeding and eating: What we know and what we don't. Curr Psychiatry Rep. 2021. https://doi.org/ 10.1007/s11920-021-01271-7.

42. Kutz AM, Marsh AG, Gunderson CG, Maguen S, Masheb RM. Eating disorder screening: a systematic review and meta-analysis of diagnostic test characteristics of the SCOFF. J Gen Intern Med. 2020. https://doi.org/ 10.1007/s11606-019-05478-6.

43. Starcevic V, Aboujaoude E. Internet addiction: reappraisal of an increasingly inadequate concept. CNS Spectr. 2017. https://doi.org/10.1017/ S1092852915000863.

\section{Publisher's Note}

Springer Nature remains neutral with regard to jurisdictional claims in published maps and institutional affiliations.
Ready to submit your research? Choose BMC and benefit from:

- fast, convenient online submission

- thorough peer review by experienced researchers in your field

- rapid publication on acceptance

- support for research data, including large and complex data types

- gold Open Access which fosters wider collaboration and increased citations

- maximum visibility for your research: over 100M website views per year

At BMC, research is always in progress.

Learn more biomedcentral.com/submissions 